\title{
Perinatal Influences on in Vitro B Lymphocyte Differentiation in Human Neonates
}

\author{
WILLIAM B. PITTARD, III, KATHLEEN M. MILLER, AND RICARDO U. SORENSEN \\ Department of Pediatrics, Rainbow Babies and Childrens Hospital, Cleveland, Ohio 44106
}

\begin{abstract}
In vitro differentiation of $B$ lymphocytes present in cord blood mononuclear cell preparations into immunoglobulin secreting cells was studied in 126 neonates with gestational ages (GA) ranging from 20 to 44 wk. Eight infants had a GA less than 27.9 wk, 24 had GA $28-32.9$ wk, 30 had GA 33-37.9 wk, 51 had GA 38-41.9 wk, and 13 had GA above 42 wk. B cell differentiation in response to pokeweed mitogen plus hydrocortisone was assessed using a plaque forming cell assay. All neonates had a measurable plaque-forming cell response in this assay. An increased plaque-forming cell response was observed in some neonates in all gestational age groups. The magnitude of in vitro neonatal $B$ cell differentiation underwent a continuous and significant $(p<0.002)$ reduction as gestational age increased. The influence of intrauterine growth retardation on in vitro $B$ lymphocyte differentiation was studied and compared to gestational age-matched controls with a normal intrauterine growth. Intrauterine growth retardation was not associated with changes in $B$ cell responsiveness. An analysis of perinatal factors revealed that cesarean section, and low 1-min Apgar scores were factors that predisposed cord blood cells to be triggered in vitro to produce increased numbers of plaque-forming cells. (Pediatr Res 19: 655-658 1985)
\end{abstract}

\section{Abbreviations}

ISC, immunoglobulin secreting cells

AGA, appropriate for gestational age

SGA, small for gestational age

LGA, large for gestational age

MNC, mononuclear cell

PFC, plaque-forming cell

PWM, pokeweed mitogen

HC, hydrocortisone

NK, natural killer

PROM, prolonged rupture of amniotic membranes

Human B-lymphocytes present in cord blood mononuclear cell preparations have been shown to develop into ISC under appropriate culture conditions (1-3). In vitro B-lymphocyte differentiation has been assessed only in term newborns who were appropriately grown for their gestational age. We have measured cord blood B-lymphocyte differentiation into ISC's in both premature and full term neonates and in infants who have sustained normal and retarded intrauterine growth. Our study patients

Received February 1, 1984; accepted February 20, 1985

Reprint requests to William B. Pittard, III, M.D., Department of Pediatrics, Rainbow Babies and Childrens Hospital, 2101 Adelbert Road, Cleveland, OH 44106.

Supported in part by NIH Grant 1-RO1-MD15183. range from 20 to $44 \mathrm{wk}$ gestational age and include 62 premature (less than 38 wk gestation) and 64 term (equal to or greater than 38 wk gestation) neonates. Of these neonates 97 were AGA, 17 SGA, and 12 LGA for their gestational age. Our results suggest that B lymphocytes present in cord blood MNC preparations isolated from neonates 20 to 44 wk gestation can be induced in vitro to differentiate into ISC's. ISC development was observed in some infants from each gestational age group, with the greatest ISC response being observed in infants from the lowest gestational age group. In analyzing the perinatal influences which may have predisposed cord blood cells to increased ISC development in vitro, we found that intrauterine growth retardation was not a significant factor. Although no single parameter consistently led to increased ISC development, cesarean section and low 1-min Apgar scores were associated with a significant increase in ISC production.

\section{MATERIALS AND METHODS}

Heparinized cord blood (30 U heparin per milliliter) was collected from the fetal side of the discarded placenta immediately after delivery as approved by the University Hospital $\mathrm{Hu}-$ man Experimentation Committee. The length of gestation was determined by maternal history of the last menstrual period. Where birth weight indicated non-AGA status for a given neonate, a Dubowitz examination was performed by one of the investigators (WBP) to confirm length of gestation (4). All infants were clinically normal with no evidence of an immunodeficiency syndrome. Adult venous samples were collected from healthy volunteers. All blood samples were obtained in accordance with the guidelines established by the Institutional Review Board of University Hospitals of Cleveland.

Mononuclear cell cultures. Peripheral and cord blood MNC's were obtained from heparinized blood samples by standard Ficoll-Hypaque discontinuous gradient centrifugation (Pharmacia Fine Chemicals, Piscataway, NJ). The mononuclear cells were counted with a hemocytometer and identification was confirmed in a random selection of specimens with Wright's staining. Cell cultures for the generation of PFC responses were carried out as described by Fauci et al. (5). Five $\times 10^{5}$ mononuclear cells in $1 \mathrm{ml}$ of RPMI 1640 medium containing $100 \mathrm{U} / \mathrm{ml}$ of penicillin, $100 \mu \mathrm{g} / \mathrm{ml}$ of streptomycin, $10 \%$ heat inactivated fetal calf serum (FCS), and $20 \mu \mathrm{l} / \mathrm{ml}$ of $8.4 \%$ sodium bicarbonate were incubated in $12 \times 75 \mathrm{~mm}$ round bottom plastic tubes (Falcon no. 2054).

Cell cultures were stimulated with PWM (GIBCO, $2.5 \mu \mathrm{l} / \mathrm{ml}$ ), with HC (HC sodium succinate): Solu-Cortef Upjohn; $10^{-5} \mathrm{M}$ ), or with PWM and HC together. Optimal mitogen concentrations were established in preliminary studies (3). Cultures were maintained at $37^{\circ} \mathrm{C}$ in $5 \% \mathrm{CO}_{2}$ in air at $100 \%$ humidity for 5 days prior to indirect PFC assay.

Indirect protein A PFC assay. PFC's were enumerated by the method described by Fauci et al. (5). Sheep red blood cells were 
Table 1. PFC response of mononuclear cells from neonates of different gestational age (mean \pm SE)

\begin{tabular}{|c|c|c|c|c|c|}
\hline \multirow[b]{2}{*}{ Group } & \multirow[b]{2}{*}{$n$} & \multirow{2}{*}{$\begin{array}{c}\text { Gestational age } \\
\text { (wk) }\end{array}$} & \multirow{2}{*}{$\begin{array}{c}\text { Body wt } \\
\text { (kg) }\end{array}$} & \multicolumn{2}{|c|}{$\mathrm{PFC} / 10^{6} \mathrm{MNC}$} \\
\hline & & & & PWM (alone) & $\mathrm{PWM}+\mathrm{HC}$ \\
\hline I & 8 & $24.5 \pm 0.9$ & $0.7 \pm 0.1$ & $1625 \pm 716$ & $9436 \pm 5983$ \\
\hline III & 30 & $35.4 \pm 0.3$ & $2.4 \pm 0.1$ & $662 \pm 305$ & $8893 \pm 2131$ \\
\hline IV & 51 & $39.3 \pm 0.1$ & $3.0 \pm 0.1$ & $643 \pm 197$ & $4186 \pm 800$ \\
\hline V & 13 & $42.3 \pm 0.1$ & $3.6 \pm 0.2$ & $365 \pm 239$ & $4915 \pm 1123$ \\
\hline I-V & 126 & $36.0 \pm 0.4$ & $2.4 \pm 0.1$ & $827 \pm 192$ & $7505 \pm 1058^{*}$ \\
\hline
\end{tabular}

* Value of groups I, II, and III is significantly greater than groups IV and V (term neonates): $p<0.002$.

Table 2. PFC response related to intrauterine growth status (mean $\pm S E$ )

\begin{tabular}{lccccc} 
& \multicolumn{2}{c}{$\begin{array}{c}\text { Gestational age } \\
(\mathrm{wk})\end{array}$} & $\begin{array}{c}\text { Body wt } \\
(\mathrm{kg})\end{array}$ & PWM (alone) & PWM + HC \\
\cline { 4 - 6 } & $n$ & $35 \pm 0.5$ & $2290 \pm 96$ & $791 \pm 182$ & $8364 \pm 1334$ \\
AGA $^{\text {SGA* }}$ & 97 & $38.6 \pm 0.6$ & $2008 \pm 96$ & $625 \pm 522$ & $4685 \pm 1380$ \\
LGA $^{*}$ & 17 & $40 \pm 0.5$ & $4124 \pm 74$ & $1404 \pm 1217$ & $4559 \pm 1293$ \\
\hline
\end{tabular}

* AGA, SGA, and LGA indicate neonates 10th to 90th (appropriate), less than 10th (small) and greater than 90th (large) percentile birth weight for gestational age, respectively.

coupled to purified protein A (SpA; Pharmacia Fine Chemicals) by using a chromium chloride technique (6). Cell cultures were harvested, washed, and resuspended in cold RPMI 1640 medium. Plastic Petri dishes $(60 \times 15 \mathrm{~mm}$; Falcon no. 1007) were precoated with $0.7 \%$ agarose (Accurate Chemicals, Hicksville, NY) in RPMI 1640. An ultrathin layer consisting of $100 \mu \mathrm{l}$ of resuspended cultured cells, $0.85 \mathrm{ml}$ of agarose in RPMI 1640 , and $50 \mu \mathrm{l}$ of a $15 \%$ suspension of SpA-coated SRBC was poured evenly over the agarose-precoated Petri dishes, cooled, and incubated at $37^{\circ} \mathrm{C}$ for $2 \mathrm{~h}$. The plaques were developed by layering $1 \mathrm{ml}$ of a 1:100 dilution of the IgG fraction of a rabbit antihuman polyvalent Ig (Cappel Labs, Cochranville, PA) onto the Petri dishes. The plates were then incubated overnight at $37^{\circ} \mathrm{C}$. The antiserum was removed, and $1 \mathrm{ml}$ of guinea pig complement (M.A. Bioproducts, Wakersville, MD; 1:40 in barbital buffered saline) was added. After a 1-h incubation the complement was removed and plaques were read under indirect light at $4 \times$ magnification. Data are expressed as $\mathrm{PFC} / 10^{6}$ cultured cells.

Statistical analysis. Results are presented as the mean and SEM. A standard $t$ test was employed.

Data recorded concerning each infant included gestational age, birth weight, sex, Apgar score at $1 \mathrm{~min}$, and classification as to LGA, SGA or AGA in utero (7). Recorded maternal data included age and gravidity, mode of delivery, presence or absence of ruptured amniotic membranes greater than $24 \mathrm{~h}$ prior to delivery, and presence or absence of meconium stained amniotic fluid. These clinical parameters were then compared with the lymphocyte differentiation data from the total population of neonates. The number of PFC developed per $10^{6}$ cord blood mononuclear cells in response to PWM alone and PWM plus $10^{-5} \mathrm{M}$ hydrocortisone was measured in 97 appropriately grown in utero (AGA), 17 growth retarded (SGA), and 12 LGA neonates (5). For data analysis, the 126 neonates were divided into five gestational age categories including eight infants 20 to $27 \mathrm{wk}, 24$ infants 28 to $32.9 \mathrm{wk}, 30$ infants 33 to $37.9 \mathrm{wk}, 51$ infants 38 to $41.9 \mathrm{wk}$, and 13 infants 42 to $44 \mathrm{wk}$.

\section{RESULTS}

PFC's were detected in MNC cultures from all infants in response to PWM plus $\mathrm{HC}$, whereas $50 \%$ of cord blood cultures had a minimal response to PWM alone of less than $100 \mathrm{PFC} /$ $10^{6} \mathrm{MNC}$ (Table 1). The PFC response of the cord blood lymphocytes to PWM plus hydrocortisone from all 126 neonates was significantly correlated with the PFC response to PWM alone
( $p<0.001)$. Adult MNC cultures $(n=15)$ stimulated with PWM produced a significant level of PFC's $(17,083 \pm 4356$, mean \pm SE PFC $/ 10^{6} \mathrm{MNC}$ ) that was increased to a maximum response $\left(59,949\right.$ PFC $\left./ 10^{6} \mathrm{MNC}\right)$ in the presence of both PWM and HC (data not shown). No adult or neonatal culture produced PFC's with $\mathrm{HC}$ alone.

The mean number of PFC's generated in response to PWM plus hydrocortisone significantly decreased $(p<0.002)$ as the gestational age increased from 20 to $44 \mathrm{wk}$ (Table 1). Further, the mean PFC response measured at birth was significantly greater $(p<0.002)$ in preterm infants $(\leq 37.9 \mathrm{wk}$ gestation) than it was in more mature neonates ( $\geq 38$ wk gestation).

Although PFC responses were observed in all gestational age groups, not all individuals in each group had a large response. If a range of response is established for the term neonates (group IV) of 0 to $10,000 \mathrm{PFC} / 10^{6} \mathrm{MNC}$ (mean $\pm 1 \mathrm{SD}$ of group IV), it was observed that $11.4 \%$ of group IV had PFC responses above $10,000 \mathrm{PFC} / 10^{6} \mathrm{MNC}$, whereas $40.0,38.9$, and $26.1 \%$ of groups I, II, and III had PFC responses greater than $10,000 \mathrm{PFC} / 10^{6}$ MNC.

Intrauterine growth retardation as a reflection of intrauterine placental dysfunction was not significantly related to the increased PFC value observed in the younger gestational age groups as shown in Table 2. Therefore, other parameters that might influence this PFC response were evaluated. Neither maternal age and/or gravidity, nor the infant's sex, PROM, or the presence or absence of meconium in the amniotic fluid were significantly correlated with the PFC response measured. On the other hand, the mode of delivery and Apgar score at 1-min after delivery were related to significantly increased PFC responses (Table 3).

\section{DISCUSSION}

Cord blood B-lymphocytes unlike adult B cells present in isolated MNC preparations are normally unable to differentiate into ISC when cultured in the presence of PWM alone. The data on ISC development in neonatal B lymphocytes from cord blood MNC preparations presented here were obtained using PWM plus HC stimulation of MNC and detection of ISC in a reverse plaque assay using polyvalent anti-Ig as the developing antibody. When MNC from cord blood are cultured in the presence of PWM alone, minimum levels of PFC are produced, unlike the response seen with adult MNC. Activators such as live EpsteinBarr virus $(1,8)$, killed Staphylococcus aureus $(3,9,10)$ or a combination of $S$. aureus and PWM (2) have been used to induce 
Table 3. Influence of cesarean section and low 1-minute Apgar score on neonatal PFC response (mean $\pm S E$ )

\begin{tabular}{|c|c|c|c|c|c|}
\hline \multirow[b]{2}{*}{ Group } & \multirow[b]{2}{*}{$n$} & \multirow{2}{*}{$\begin{array}{l}\text { Gestational age } \\
\text { (wk) }\end{array}$} & \multirow{2}{*}{$\begin{array}{c}\text { Body wt } \\
(\mathrm{kg})\end{array}$} & \multicolumn{2}{|c|}{$\mathrm{PFC} / 10^{6} \mathrm{MNC}$} \\
\hline & & & & PWM (alone) & $\mathrm{PWM}+\mathrm{HC}$ \\
\hline I. Vaginal delivery & 87 & $35.8 \pm 0.6$ & $2415 \pm 111$ & $669 \pm 188$ & $\begin{array}{c}6064 \pm 1028 \\
p<.05\end{array}$ \\
\hline Cesarean section & 39 & $35.8 \pm 0.7$ & $2337 \pm 163$ & $1180 \pm 459$ & $10,719 \pm 2482$ \\
\hline II. Apgar $\geq 7$ & 82 & $37.7 \pm 0.4$ & $2671 \pm 94$ & $685 \pm 250$ & $\begin{array}{c}5442 \pm 826 \\
\mathrm{p}<.008\end{array}$ \\
\hline Apgar $\leq 6$ & 44 & $32.3 \pm 0.9$ & $1870 \pm 171$ & $1092 \pm 294$ & $11,348 \pm 2528$ \\
\hline
\end{tabular}

adult levels of PFC production and intracytoplasmic immunoglobulin production from cord blood MNC cultures. We have found that stimulating cord blood MNC with PWM plus HC will amplify the response due to PWM alone. Although the response is not equivalent to adult levels, the cord blood PFC response is amplified sufficiently to detect significantly elevated responses. $\mathrm{HC}$ has been noted to enhance immunoglobulin synthesis by PWM-stimulated adult human lymphocytes (11). A direct effect of corticosteroids on the B-lymphocyte has been suggested (12), although an effect on regulatory T-cells has also been described (13). HC will inhibit both Interleukin 1 (14) and Interleukin $2(15,16)$ production to certain degrees. Both Interleukin-1 and Interleukin-2 are potent regulator proteins in the induction of the immune response because of their ability to control proliferation and the production of differentiation factors. A decrease of Interleukin-2 without a decrease of B-cell growth-promoting activity will enhance B cell proliferation (17). A combination of the effects of $\mathrm{HC}$ may partly explain the enhancement of PFC production in adults. Whether a similar mechanism may account for the enhanced PFC development in the neonate needs to be elucidated. In this investigation, we used the enhancement of neonatal PFC's to study the influence of perinatal events on the development of immunoglobulin secreting cells in vitro.

Our data show that mononuclear cells isolated from the cord blood of neonates of varying gestational ages can be induced under appropriate in vitro conditions to develop a significant number of ISC's. Although each gestational age group was able to show this response, the greatest level of ISC was observed in the early gestational age groups. This increase in in vitro ISC development in the most immature groups of neonates was puzzling, since as the fetus matures the capacity for immunoglobulin synthesis increases. Since it was also observed that some individuals from each group produced significant levels of PFC's but others from the same group did not, parameters other than neonatal maturity were sought as an explanation for increased PFC development in the LGA infant.

When the PFC responses of the entire population were evaluated it was noted that some perinatal events were associated with an increased ability of circulating B lymphocytes to develop into ISC in vitro. Delivery by cesarean section and Apgar scores of 6 or less at 1 -min were each associated with a significantly greater PFC response than that measured in neonates not exposed to these perinatal influences. Each perinatal factor regarded individually could be shown to have an influence on increased PFC development. However, these perinatal factors frequently occur in the same individual, and it becomes difficult to attribute increased PFC development to any single factor. Premature infants are more likely to have low Apgar scores at birth than term infants. Therefore, increased PFC responses are not solely the result of LGA. Term infants associated with these perinatal factors also had higher responses than term infants not exposed to them.

Whether a constant mechanism predisposing neonatal B lymphocytes to increased in vitro development into ISC is present in neonates delivered by cesarean section and in infants with low 1-min Apgar scores cannot be defined from the data presented herein. Further studies will be necessary to elucidate this question.

The significantly increased PFC response among the neonates delivered by cesarean section as compared to vaginally delivered infants is of interest. Neonatal lymphocyte mitogen induced proliferation has recently been noted to be significantly increased in cesarean section versus vaginally delivered infants (18). In contrast, NK cell activity has been reported to be decreased in surgically delivered neonates (19). These observations support a mechanism of immunoregulation by NK cells (20). Abruzzo and Rowley (21) have recently reported that NK cells promote early termination of an ongoing primary immunoglobulin M PFC response and that the target for NK cells is a population of accessary cells that has interacted with antigen and is necessary for sustaining the antibody response. We are now exploring the effect of cesarean section with and without labor and of vaginal delivery on several parallel immune functions in order to gain further insight into this observation.

Suppressor T-cells and related suppressor factor mechanisms have been invoked to explain the diminished immune responsiveness of the neonate (22-24). Several studies using monoclonal T-cell markers have shown that the neonate has normal numbers of circulating T-cell subpopulations (25-27). These reports have not evaluated the influence of perinatal events on T-cell subpopulations. Preliminary studies in our laboratory have revealed a significantly higher proportion of OKT8 positive T-lymphocytes in newborns delivered after maternal labor, as compared to newborns delivered by elective cesarean section in absence of labor (Pittard III WB, unpublished observation). Although one report suggests that the suppressor activity in the newborn is a function of lymphocytes expressing the OKT4+ (helper/inducer) phenotype, the suppression exerted by this subpopulation is not greater than the suppression caused by the OKT $8+$ (suppressor) population in adults (28). Whether the observed changes in $T$ lymphocyte subpopulations correlate with the observed increased lymphocyte proliferative response and increased PFC response in neonates delivered by cesarean section needs to be determined.

The increased PFC response seen in infants with low Apgar scores may be due to factors different from those operative in cesarean section. Stress is likely to be present in some of these neonates. It is interesting to postulate that stress may have an effect on immunoregulatory cells, producing changes in the immune response capabilities which may be detected through functional testing as done in this investigation.

Intrauterine and neonatal infections can lead to an increased immunoglobulin production in vivo (29). Our study population did not include neonates with clinically recognizable intrauterine infection. PROM is associated with an increased incidence of neonatal infection and sepsis (30). As a single perinatal factor, PROM was not associated with increased PFC development in our study. This could be due to the relatively short lapse of time between a possible antigen exposure caused by PROM and the collection of the cord blood sample used in our assay. On the other hand, our PFC assay does not detect in vivo B-cell differentiation and immunoglobulin production. Rather, it measures the extent neonatal B-lymphocytes respond to in vitro stimulation by polyclonal-B-lymphocyte activators. The conditions that 
lead to an increased B-lymphocyte responsiveness in vitro do not appear to be related to in vivo exposure of T-and B-lymphocytes to bacterial antigens.

In summary our results indicate that active in vitro development of PFC's can be observed in some neonates at all gestational ages beyond $20 \mathrm{wk}$. Several clinical settings are identified which are associated with increased neonatal PFC development in vitro, but none of these perinatal factors consistently leads to increased PFC responsiveness. The higher PFC levels at lower gestational age may reflect a higher incidence of such predisposing factors in premature newborns.

\section{REFERENCES}

1. Bird AG, Britton S 1979 A new approach to the study of human B lymphocyte function using an indirect plaque assay and a direct $B$ cell activator. Immunol Rev 45:41-67

2. Miller KM, Pittard WB, Sorensen RU 1984 Synergistic effect of pokeweed mitogen and Staphylococcus aureus on in vitro differentiation of B-cells from human neonates. Clin Exp Immunol 56:415-424

3. Ruuskanen O, Pittard W, Miller K, Pierce G, Sorensen RU, Polmar SH 1980 Staphylococcus aureus Cowan I-induced immunoglobulin production in human cord blood lymphocytes. J Immunol 125:411-413

4. Dubowitz LMS, Dubowitz V, Goldberg C 1970 Clinical assessment of gestational age in the newborn infant. J Pediatr 77:1-10

5. Fauci AS, Whalen G, Burch C 1980 Activation of human B lymphocytes. XVI. Cellular requirements, interactions, and immunoregulation of pokeweed mitogen-induced total immunoglobulin producing plaque-forming cells in peripheral blood. Cell Immunol 54:230-240

6. Gronowicz E, Coutinho A, Melchers F 1976 A plaque assay for cells secreting Ig of a given type or class. Eur J Immunol 6:588-590

7. Sweet AY 1979 Classification of the low birth weight infant. In: Klaus MH, Fanaroff AA (eds) Care of the High-Risk Neonate. WB Saunders Co, Philadelphia, pp 66-93

8. Tosato G, Magrath I, Koski I, Dolley N, Blaese RM 1980 B cell differentiation and immunoregulatory $\mathrm{T}$ cell function in human cord blood lymphocytes. J Clin Invest 66:303-388

9. Andersson U, Bird G, Britton S 1980 Cellular mechanisms of restricted immunoglobulin formation in the human neonate. Eur J Immunol 10:888894

10. Romagnani S, DelPrete GV, Maggi E, Falagiani P $1980 \mathrm{~T}$ cell independence of immunoglobulin synthesis by human peripheral blood lymphocytes stimulated with SpA-containing staphylococci. Immunology 41:921-922

11. Cooper DA, Duckett M, Hansen P, Petts V, Penny R 1981 Glucocorticosteroid enhancement of immunoglobulin synthesis by pokeweed stimulated human lymphocytes. Clin Exp Immunol 44:129-136

12. Cooper DA, Duckett M, Petts V, Penny R 1979 Corticosteroid enhancement of immunoglobulin synthesis by pokeweed mitogen-stimulated human lymphocytes. Clin Exp Immunol 37:145-151
13. Grayson J, Dooley NJ, Koski IR, Blaese RM 1981 Immunoglobulin production induced in vitro by glucocorticoid hormones. J Clin Invest 68:1539-1547

14. Snyder DS, Unanue ER 1982 Corticosteroids inhibit murine macrophage Ia expression and Interleukin-1 production. J Immunol 129:1803-1805

15. Chouaib S, Fradelizi D 1982 The mechanism of inhibition of human IL-2 production. J Immunol 129:2463-2468

16. Walker C, Kristensen F, Bettens F, deWeck AL 1983 Lymphokine regulation of activated $\left(G_{1}\right)$ lymphocytes. $I$. Prostaglandin $E_{2}$-induced inhibition of interleukin 2 production. J Immunol 130:1770-1793

17. Maizel A, Mehta S, Kouttab N, Morgan J, Ford R, Sahasrabuddhe C 1983 Proliferation of human B-lymphocytes mediated by a soluble factor. Fed Proc 42:2753-2756

18. Pittard W, Miller K, Sorensen R 1984 Normal lymphocyte responses to mitogens in term and premature neonates following normal and abnormal intrauterine growth. Clin Immunol Immunopathol 30:178-187

19. Frazier JP, Kohl S, Pickering L, Loo L-S 1982 The effect of route of delivery on neonatal natural killer cytotoxicity and antibody-dependent cellular cytotoxicity in Herpes Simplex virus infected cells. Pediatr Res 16:558-560

20. Katz DR 1984 Immunosuppression as a physiological homeostatic mechanism. Immunol Today 5:96-97

21. Abbruzzo LV, Rowley DA 1984 Homeostasis of the antibody response: immunoregulation by NK cells. Science 222:581-585

22. Lydyard PM, Hayward AR 1979 Induction of suppression through human Tcell interactions. Clin Exp Immunol 39:496-502

23. Miyawaki T, Moriya N, Nagaoki T, Kubo M, Yokoi T, Taniguchi N 1981 Mode of action of humoral suppressor factor derived from pokeweed mitogen-stimulated cord $T$-cells on adult $B$ cell differentiation. J Immunol 126:282-285

24. Nagaoki T, Moriya N, Miyawaki T, Seki H, Kubo M, Yokoi T, Okuda N, Taniguchi $N 1980$ Suppression of $B$ cell differentiation by dialyzable humoral factors derived from pokeweed mitogen-stimulated cord T cells. J Immunol 125:1563-1568

25. Hayward AR, Kurnick J 1981 Newborn T cell suppression: early appearance, maintenance in culture and lack of growth factor suppression. $\mathbf{J}$ Immunol 126:50-53

26. Kamps WA, Cooper MD 1984 Development of lymphocyte subpopulation identified by monoclonal antibodies in human fetuses. $\mathrm{J}$ Clin Immunol 4:36-39

27. Maccario R, Nespoli L, Mingrat G, Vitiello A, Ugazio AG, Burgio GR 1983 Lymphocyte subpopulations in the neonate: identification of an immature subset of the OKT8-positive, OKT3-negative cells. J Immunol 130:1129113

28. Yachie A, Miyawaki T, Nagaoki T, Yokoi T, Mukai M, Uwadana N, Taniguchi N 1981 Regulation of $B$ cell differentiation by $T$ cell subsets defined with monoclonal OKT4 and OKT8 antibodies in human cord blood. $\mathrm{J}$ Immunol 127:1314-1317

29. Alford CA 1971 Immunoglobulin determinations in the diagnosis of fetal infection. Pediatr Clin North Am 18:99-113

30. Pryles CV, Steg NL, Nair S, Gellis SS, Tenney B 1963 A controlled study of the influence on the newborn of prolonged rupture of the amniotic membranes and/or infection in the mother. Pediatrics 31:608-621 